\title{
Online Communication using Discussion Boards
}

Ros O'Leary, The Economics Network, University of Bristol

1 Introduction 2

$\begin{array}{ll}1.1 & \text { What are discussion boards? }\end{array}$

1.2 Why use discussion boards in economics teaching? 4

1.3 How can discussion boards be used to enhance learning?

$\begin{array}{lll}2 & \text { Effective teaching with discussion boards: practical tips } & 7\end{array}$

$\begin{array}{lll}2.1 & \text { Ensuring sufficient practical support } & 7\end{array}$

$\begin{array}{lll}2.2 & \text { Setting objectives } & 7\end{array}$

$\begin{array}{lll}2.3 & \text { Student induction and ongoing support } & 7\end{array}$

$\begin{array}{lll}2.4 & \text { Agreeing rules and roles } & 7\end{array}$

$\begin{array}{lll}2.5 & \text { Encouraging use of common language and tone } & 8\end{array}$

$\begin{array}{lll}2.6 & \text { Grouping students } & 8\end{array}$

$\begin{array}{llr}2.7 & \text { Building an online community } & 9\end{array}$

$\begin{array}{ll}2.8 \text { Evaluation } & 9\end{array}$

3 Different uses of discussion boards for economics teaching 10

$\begin{array}{llr}3.1 & \text { Building FAQs } & 10\end{array}$

3.2 Role-plays and simulations 11

$\begin{array}{llr}3.3 & \text { Virtual seminars } & 12\end{array}$

$\begin{array}{lll}3.4 & \text { Structured debates } & 15\end{array}$

$\begin{array}{lll}3.5 & \text { Master classes } & 16\end{array}$

$\begin{array}{lll}3.6 & \text { Co-operative/collaborative project work } & 17\end{array}$

4 Conclusions $r$

$5 \quad$ Where next? 18

$\begin{array}{lr}\text { References } & 19\end{array}$ 


\section{Introduction}

This chapter introduces online communications focusing on text-based computer communication, such as discussion and bulletin boards. Such online communication is sometimes referred to as computer mediated communication (CMC).

Some of the advantages (and disadvantages) of using discussion boards as a tool for teaching are discussed, as well as some approaches to effective economics teaching using this technology. The chapter also draws on and presents some current theory and practice in this area, gives practical advice about using discussion boards effectively and provides examples of activities, using case studies as illustrations.

\subsection{What are discussion boards?}

Discussion or bulletin boards are commonly provided in Virtual Learning Environments (VLEs) such as Blackboard and WebCT. They provide the facility for students and tutors to hold discussions and contact each other in groups.

They allow students to:

- contact tutors on an individual basis;

- collaborate on and share tasks, including the exchange of files;

- provide each other with feedback;

- raise questions;

- participate in open discussion;

- share experiences, ideas and resources.

They allow teachers to:

- contact students individually;

- provide an answer to an individual question to all students;

- put students into tutor or other groups to work together;

- facilitate collaborative discussions and activities;

- provide reminders and information.

Discussions are threaded: in other words, the relationship between a message and the responses posted to it is displayed graphically on screen in a way that gives a meaningful structure to a discussion or activity (see Figure 1). Discussions are also recorded, enabling students and the tutor to return to discussions. 


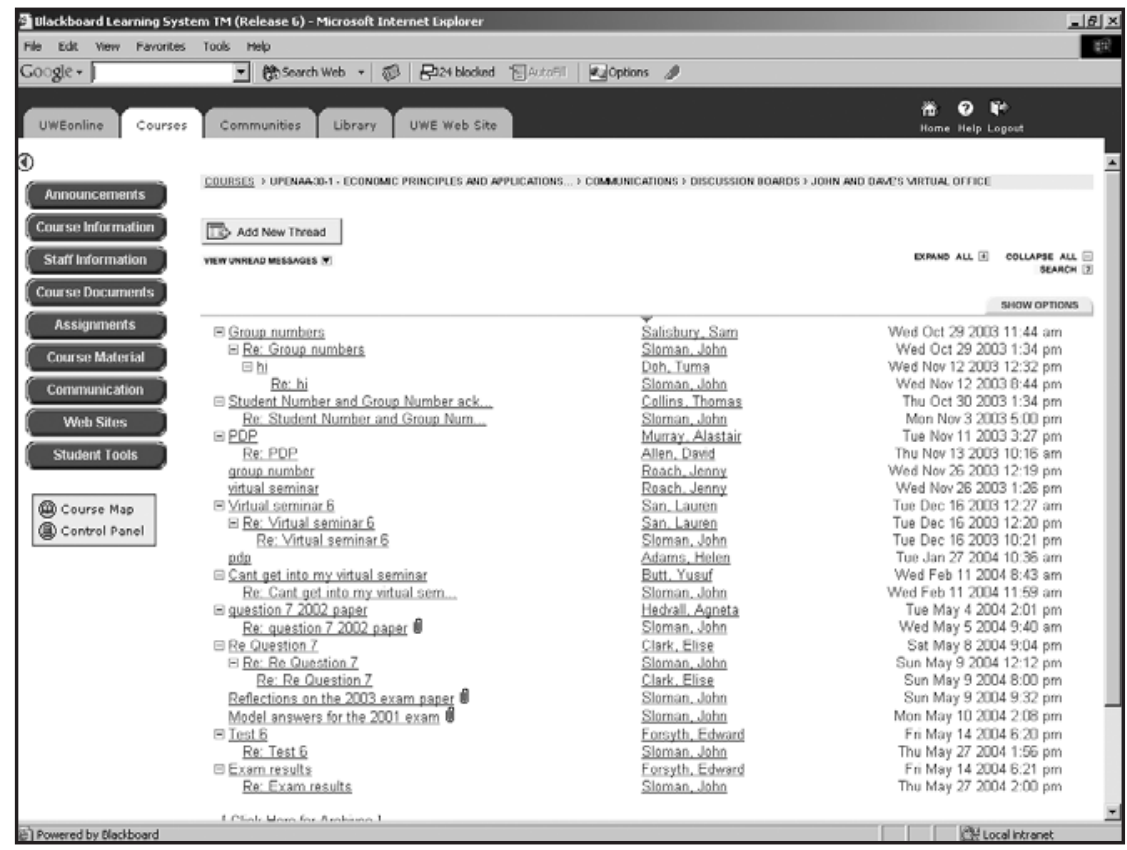

Figure 1. Example of a discussion board from Blackboard

This discussion board is a 'virtual office', which shares individual student questions with the whole community. Figure 2 shows an excerpt from the same discussion board - note that one of the answers has been read 66 times.

\section{Current Forum: John and Dave's Virtual Office}

Date: Tue May 42004 2:01 pm

Author: student 1

Subject: question 72002 paper

Hello John and Dave,

Could you please give and explain the answer to question no 7 on the 2002 paper? The info for mps, mpt and mpm plus mpcd and injections are given but I do not understand how to calculate the mpcd using that info.

thanks

Current Forum: John and Dave's Virtual Office

Read 66 times

Date: Wed May 52004 9:40 am

Author: John

Attachment: model_answers_q7.doc (22016 bytes)

Subject: Re: question 72002 paper

Hi there

I'm attaching a model answer for Q7. Hope that answers your questions.

All the best, John

Figure 2. Excerpt of discussion from the same discussion board. (Continued over). 
Current Forum: John and Dave's Virtual Office

Read 31 times

Date: Sat May 82004 9:04 pm

Author: student 2

Subject: Re Question 7

I have just tried to answer the question before using the model answer. Even with the help of the model answer I can't understand what happens when the government spends an additional $£ 10 \mathrm{~m}(\mathrm{~d})$

I can't work out whether gov expenditure is T or $G$ and how you get to the end result of an equilibrium of $£ 75050$.

Please could you let me know of the way to work this out?

Thanks.

Current Forum: John and Dave's Virtual Office Read 35 times

Date: Sun May 92004 12:12 pm

Author: John

Subject: Re: Re Question 7

Hi there

The initial equilibrium level of national income is $£ 75,000 \mathrm{~m}$ (i.e. $£ 65,000 \mathrm{~m}+£ 10,000 \mathrm{~m}$ ).

A rise in $\mathrm{G}$ of $£ 10 \mathrm{~m}$ is an increase in injections of $£ 10 \mathrm{~m}$. This will be multiplied by the multiplier of 5 , giving a rise in national income of $£ 50 \mathrm{~m}$ from $£ 75,000 \mathrm{~m}$ to $£ 75,050 \mathrm{~m}$.

Hope that helps

Cheers

John

Figure 2 Excerpt of discussion from the same discussion board

\subsection{Why use discussion boards in economics teaching?}

Larger class sizes, less resources and an increasingly diverse range of students (Reynolds, 2000) have put pressure on economics higher education to explore new ways of teaching. In addition to catering for overseas students from an increasing range of countries, economics courses are also more likely than previously to be enrolling students who are mature, studying part-time or possessing qualifications other than traditional A-levels. Against such a backdrop, economics teachers have been seeking new ways to engage and motivate students, while dealing with the practical problems of maintaining the quality of teaching with larger numbers of students.

Online discussions offer opportunities to manage classes on a 'distributed' basis. They can provide a shared 'workspace', offer a place to answer common queries and facilitate mixed timetable demands across a student group. They can also create a flexible environment for tutors and students with regard to time and space, and offer some unique benefits to learning when used effectively. 


\subsection{How can discussion boards be used to enhance learning?}

'The most powerful anecdote, that changed my thinking about ...working through a computer mediated communication [and] not being face-to-face with students was a discussion that I had with a year three student, part of a seminar session where she was talking about web boards [discussion boards] ... and this was a young woman sitting in a group of other young women, but she was very plain in comparison to the others in the group, very poorly dressed in comparison to the rest of the group and she said she loved the use of web boards because people judged her on what she wrote and not on what she looked like.

There was a totally stunned silence in the group in which she had worked with for three years, because they had never ever understood the kind of feeling that she felt interacting with them as a group of people. She loved it. She loved the fact that she could stop and think, she could pause her thoughts, ... and she didn't have to come up with lots of articulate ideas within the group setting and she could actually concentrate on it, she could go and get her references and then she could go on and construct her argument. And people judged her on the strength of her argument and not what she looked like or any peripheral information about her.'

Students' Online Learning Experiences (SOLE) project, case study tutor interview, 2003

This particular student had a preference for online learning, where the lack of visual clues may preclude judgements and anonymity can encourage shy learners to participate (Freiermuth, 2001).

The student also enjoyed being able to spend time on her contributions: Goodyear (2001) argues that the time spent on creating replies to discussion board postings enables a reflective and 'deeper' processing of knowledge.

Other perceived benefits of using discussion boards in learning are as follows:

- It offers students the flexibility of being able to be participate in learning any time, any place. The disadvantage of this flexibility is a lack of immediacy, since students may have to wait for responses and feedback, which might result in frustration or loss of motivation.

- Discussions/contributions are recorded, which enables students and tutors to return to review activities or access answers to queries by others.

- It aids the development of important transferable skills. For example, discussion boards may facilitate the development of 'virtual' written discussion skills, potentially linking to key skills for economics students. The ability to discuss and analyse government policy and to assess the performance of the UK and other economies is listed as an indicative attainment for students in the QAA economic subject benchmark statement (2000).

Zapalska et al. (2004) report that in an economics undergraduate distance-learning programme, the use of discussion board tools alongside the provision of content (all within WebCT) improved the quality of the students' learning in the following areas: critical thinking; problem solving; decision-making ability; aptitude for detail; written communication; knowledge of information; and ability to organise and analyse. Students used the discussion board tools to discuss course concepts, to share work experiences and to offer one another suggestions for carrying out assignments and improving learning.

\section{Collaborative learning}

A central argument in current thinking about using discussion boards in learning focuses on collaborative learning.

Collaborative learning (Klemm and Snell, 1996) is 'the idea that small, interdependent groups of students work together as a team to help each other learn'. Vygotsky's (1978) Zone of 
Proximal Development focuses on cognitive development and presents the view that learning in a social context enables learners to refine their thinking, building or 'constructing' new ideas from their existing knowledge and achieving a deeper understanding than if they were learning alone. Klemm and Snell (1996) contend that one of the best ways to achieve a deeper understanding, or a higher level of learning, is through online collaborative learning: for example, using discussion boards.

\section{How might teacher and student roles change?}

Goodyear (2001) has derived indicators of teacher and student role changes when moving from 'traditional' teaching (for example, lectures) to online learning, which involves collaborative online learning.

Teachers' roles may change as follows:

- from oracle and lecturer to consultant, guide and resource provider;

- from provider of answers to expert questioner;

- from provider of content to designer of student learning experiences;

- from exercising total control of the teaching environment to sharing with the student as fellow learner;

- increasingly providing only the initial structure for student work, encouraging more selfdirection;

- displaying greater sensitivity to student learning styles.

Students' roles may also change:

- from passive receptacles for hand-me-down knowledge to constructors of their own knowledge;

- from memorisers of facts to complex problem-solvers;

- increasingly refining their own questions and searching for their own answers;

- working as group members on more collaborative/cooperative assignments;

- acting as autonomous, independent, self-motivated managers of their own time and learning process;

- using knowledge rather than merely observing the teacher's expert performance or learning to pass the test. 


\section{Effective teaching with discussion boards: practical tips}

\subsection{Ensuring sufficient practical support}

When deciding whether to use a discussion board for learning, you need to be confident about the availability of suitable resources, such as technology, software and human support. For example, will your students have sufficient access to technology or to human support when things go wrong? If insufficient support is available, this will have a demotivating effect on students, who will be less likely to participate and engage with learning.
TOP
TIPS

Make sure students have adequate access to computers and computer support when they are both on and off campus.

\section{TOP TIPS}

Consider linking discussion board activities to assessment. For example, participation in online discussion might form a small percentage of a unit's credit points, or written reflection on an activity might be part of a student's portfolio (which in itself might be a small percentage of total credit points).

For example, in the Open University's Applications of Information Technology in Open and Distance Education course (2004), students are required to reflect on the process of their online learning as an integral part of an activity that involves a group debate and follow-up essay assignment. As part of the criteria for their assignment, students are required to show how their own input has contributed to the overall debate.

\subsection{Setting objectives}

Be clear about why you are using an online discussion board within a course and how this relates to the learning outcomes. For example, are you aiming to develop students' written and discussion skills, collaborative or group working skills, or extending their contact time on a face-to-face course? Be explicit with students about why online communication is being used in the course and about what is expected from them.

\subsection{Student induction and ongoing support}

Although students are increasingly arriving at university with a higher level of IT skills and appear familiar with searching the Web for information, they may never before have engaged in any form of active online learning and will need guidance and support to do so successfully. It is important, therefore, to establish and plan how students will be supported throughout their engagement with online learning, such as with induction and ongoing support (for example, a helpdesk for technical queries or tutorials for academic queries), and to deal with any assessment issues that need to be addressed.

\begin{tabular}{|l|}
\hline TOP \\
\hline A getting-to-know-you \\
session can be a good way to \\
guide students through both \\
the technical and new skill \\
aspects of using discussion \\
boards. If possible, this should \\
be done face-to-face. \\
\hline
\end{tabular}

\subsection{Agreeing rules and roles}

Interactions with students online will be very different from those experienced during face-to-face sessions. When teaching online you will not have the same signals that you get in face-to-face teaching to indicate how students are progressing. For example, in a face-to-face tutorial you have the 
opportunity to question students, hear their tone of voice and observe their body language. Online you will not have these. Equally, students will miss non-verbal cues from each other and from you. Therefore, you need to encourage students to seek feedback, guidance and clarification proactively, both from you and from each other.

It might be necessary to establish clear guidelines on:

- length, number and academic style of student communications;

- responselfeedback timescales from teachers. If students know when tutors are likely to respond (for example, on Mondays and Fridays between 9 a.m. and 10 a.m.), they are less likely to become demotivated.

- the nature of teacher involvement. Gilbert-Hunt and McLaine (2000) argue that if tutors are not actively involved in online activities, students take more ownership. Clear guidelines on the nature of participation will be important to achieve this.

\subsection{Encouraging use of common language and tone}

'No two languages are ever sufficiently similar to be considered as representing the same social reality.'

Tan (1990, p. 27)

When working with students from different cultures and/or with different first languages, online communication problems can occur. Goodyear (2001) argues that the lack of non-verbal cues (for example, intonation, body language and gestures) can make the environment feel impersonal and can lead to misunderstandings. Ting-Toomey (1999) and Morse (2004) further contend that those from different cultures may more problems than others, as they may be communicating in a second language and/or with a different communication style, leading to misunderstandings and a lack of motivation to participate.

Findings from one of the Students' Online Learning Experiences (SOLE) project economics case study (2003) showed that guidelines about how to participate and in what style were missing. This was further confused by a mix of informal and formal contributions from the tutor. Additionally, many students were non-native English speakers with different cultural learning styles and communication preferences.

\subsection{Grouping students}

Many factors, including gender, cultural background and ability, are considerations for the mix of online groups. For example, face-to-face group studies tend to show that males dominate in mixed-gender groups (see, for example, Lockheed and Harris, 1984) and this has been replicated in online discussion (such as Hardy et al., 1994).

Group size is another important factor and many of the online discussion activities discussed in this chapter are generally best suited to small groups. Too large a group may lead to free-riding or 'lurking', and too small a group may suffer from the lack of different views or, particularly in an online situation, a critical mass for a lively discussion. Goodyear (2001) suggests that the minimum group size ought to be 5 - the actual group size will also be dependent on the type of activity.

\section{TOP \\ TIPS}

Set or negotiate clear ground rules and roles for using a discussion board right at the beginning of a course or unit. An early activity (perhaps part of induction) might involve a discussion about or the setting of online protocols.

Examples of recommended
styles of online communication
for learning include:
- Kennedy and Duffy's (2000)
principles of PACE
(Participation, Addition,
Constructive criticism and
Encouraging), which they
advocate for both students
and tutors;
- Wegerif's (1998, p. 48)
recommendation that
online communication
should be 'democratic,
respectful, open to
challenges, prepared to
give grounds for statements
and seeking critically
grounded consensus'.

TOP

To help overcome misunderstandings and ensure that learners have a shared approach to communicating online, make sure you devote some time and support to encouraging a common use of language and tone.

Examples of recommended styles of online communication principles of PACE (Participation, Addition, Constructive criticism and Encouraging), which they advocate for both students

Wegerif's (1998, p. 48) recommendation that respectful, open to challenges, prepared to and seeking critically 


\section{TOP \\ TIPS}

One way of encouraging effective participation within an online group is to assign students with different roles, such as 'summariser', 'coach', 'encourager' and 'recorder'. Some roles may be better at engaging students with 'deeper learning' than others, but rotating roles can ensure that all students get a chance to experience the different roles and different approaches.

\section{TOP}

Getting-to-know-you activities at the beginning of a course are an important step in building an online community. Brown (2001) describes online community building as a three-step process involving making friends, acceptance or conferment of the community, and camaraderie.

\subsection{Building an online community}

'Those students who possess strong feelings of community are more likely to persist than those students who feel alienated and alone.'

Rovai (2002)

Tinto (1993), Rovai (2002) and Wegerif (1998, p. 34) argue that the social dimension of learning is particularly important when considering online communities of distance learners. Wegerif reports that a study of such learners found that 'individual success or failure on the course depended upon the extent to which students were able to cross a threshold from feeling like outsiders to feeling like insiders'.

The social dimension and sense of community of learners who meet face-toface and online is arguably still important to effective learning and consideration needs to be given to how to support this process.

Other tips for encouraging and sustain successful online learning communities include:

- structuring exercises to move from structured to open (Wegerif, 1998). So as the students move through the course, and as their confidence grows, they are allowed more choice and control in activities.

- allowing learners control over their learning environment. Ponti and Ryberg (2004) argue that designers need to recognise learners as creative and active producers, and that learner control of the structure of their learning environment is important for both learning and effective socialisation. This is difficult to achieve in some common discussion board tools: for example, in Blackboard or WebCT. An alternative is allocating a discussion board for students to chat to each other without any tutor involvement.

- ensuring assessment reflects 'a sense of community and promotes and rewards collaboration' (McConnell et al., 2004, p. 288). So, for example, if one of the course learning outcomes focuses on collaboration, assessment needs to reflect this through group assessment or personal reflection on the collaborative process.

\subsection{Evaluation}

An important aspect of teaching, especially when venturing into new areas, is continual reflection on and improvement of teaching practice. Effective evaluation needs to be planned at the start of the development process and could include:

- interviews;

- focus groups;

- end-of-course questionnaires;

- analysis of discussion board communication;

- integrating an element of reflection and critical analysis on online activities within student tasks and assignments.

More advice about evaluation approaches, methods and techniques can be found in Oliver and Conole's (1998) evaluation framework and Harvey's (1998) Evaluation Cook Book. 


\section{Different uses of discussion boards for economics teaching}

This section suggests a range of different online discussion activities suitable for economics teaching, including building FAQs, debates, virtual seminars, role plays and master classes. Case studies are used to illustrate some of these ideas and convey some of these issues that might be encountered.

\subsection{Building FAQs}

Using discussion boards to build a body of Frequently Asked Questions to be reused beyond a course can be an efficient way to use the technology. Encouraging students to post questions publicly on a discussion board, rather than contacting a tutor individually, can enable the tutor to share answers to FAQs easily, and not to duplicate effort by answering the same question many times.

The following case study outlines Professor Tony Brewer's experience of using a discussion board for this purpose.

\section{Case study 1: Building FAQs using a discussion board Professor Tony Brewer, University of Bristol, 2000}

http://www.economics.ltsn.ac.uk/showcase/brewer_discuss.htm

I have been trying out discussion boards for my students. The results so far are rather mixed, but it may be helpful to others to summarise the position. I would be very interested to hear from anyone else who has tried the idea out.

I first set up a board for a large introductory microeconomics course (180 students) in the month or so preceding the exams last summer (April-May 2000). I normally get a lot of students knocking on my office door during the revision period, but most were diverted to the board. There were about 70 postings from students during this period, ranging from questions about the exam format to detailed questions about particular lectures. In almost all cases, the student asked a fairly specific question and I responded. The same could be done by e-mail or face-to-face, but the big advantage of the board is that everyone can see the reply. It built up into a compendium of replies to questions about almost all aspects of the course.

After that experience, I set up boards for two courses of my own from the

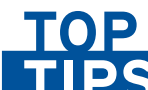
TIPS

Set out clear guidelines for students on raising questions via a discussion board to encourage participation and effective use. start of this year and a number of my colleagues followed suit. We have a total of ten boards open for use in the department, but last summer's success has not yet been repeated. October-November ( $\mathrm{I}$ am writing in late November) is evidently different from the exam-revision period. My board for the first years has yet to attract a single posting from a student. Some boards for second-year courses are a bit more active, probably because these students experienced my revision-period board last year and are accustomed to the idea, but even these have seen only a handful of postings. We need to think about how we can kick-start 
discussion, or perhaps we have to decide that boards are only worth running during the examrevision period. Any suggestions?

It is possible to restrict access but I have not found any need to do so. The risk of an outsider posting messages about my economics courses is small, and I have no objection to outsiders reading about the course. I can delete any inappropriate messages, but have rarely needed to do so.

Professor Brewer continues to use discussion boards in this way, but now uses Blackboard, which overcomes the potential problems of public access that he mentions.

\subsection{Role-plays and simulations}

Using a discussion board for role-play or simulation can be an effective way to engage students in economic concepts and actions.

\section{Case study 2: An anonymous asynchronous role play Mark Freeman and John Capper, University of Technology, Sydney, 1999}

http://www.ascilite.org.au/ajet/ajet15/freeman.html

Freeman and Capper (1999) report on how they used a discussion board to simulate a scenario in business finance for postgraduate business students on a campus-based course. Each student was assigned a role involved in the process of deregulating Australian securities markets. All students were anonymous: that is, their true identity was not revealed and only their role in the simulation was apparent.

Students had a week to research the role they were to play and then posted their profile, which included their perceptions of the concerns, ambitions and strategies of their role, to the discussion board. This summary formed the basis from which they were to participate in the role simulation. The students then responded in role over 10 days to a series of events (for example, currency crises), announced through 'press releases' to the group. Press releases were developed to ensure realistic and relevant dilemmas that allowed all roles some chance of participating. The students could respond in role through the 'public' discussion board, or could approach each other privately in role via e-mail. Students were assessed on their role profile and their private and public messages. To reward participation in the role-play, 15 per cent of marks were allocated to the role-play ( 5 per cent each to the role profile, quantity and quality of input).

Students reported a better understanding of different scenarios and a better understanding of real-world pressures as a result of the role-play. Freeman and Capper argue that by keeping the identity of the student playing each role anonymous, issues of gender and cultural expectations evident in face-to-face encounters were minimised.

\section{Other examples of using role-play and simulations}

World Trade Organisation role-play. Students take the roles of participants (a) before and (b) at a WTO meeting. An initial scenario could be given, such as the imposition of steel tariffs by the USA, and then students in groups of three would respond in role. Groups could include:

- the WTO;

- the US administration;

- the EU Commission;

- an environmental pressure group;

- a group of developing countries, such as the G21; 
- a labour organisation group in the USA;

- a labour organisation group in the UK or EU generally.

First, the students would use the group discussion board feature to agree their own group's case before the WTO, negotiating with the other two students in their group. Second, using a single discussion board, the whole class would simulate the WTO meeting. Each of the subgroups would sit round a single computer. A WTO group would chair the meeting and ensure that the discussion was structured. Alternatively, the tutor could play the role of the WTO. The discussion could be based on a real case, with hyperlinks from the discussion board to relevant references from the WTO (www.wto.org) or from sources such as The Economist (www.economist.com) and www.oneworld.net.

A meeting of ministers at a pre-government spending round meeting. Each minister would argue the case for spending in his or her area and challenge the spending demands of other ministers. The debates could take place in alternative macroeconomic scenarios, such as a recession with spending currently breeching limits (such as the Golden Rule), or a situation of budget surplus with the prospects of sustained economic growth. One student could play the chancellor, who would chair the meeting and introduce various elements into the debate, such as the plans of the Opposition, new economic shocks and the views of the prime minister. Pre-reading could include hyperlinks to the Economic and Fiscal Strategy Report at www.hm-treasury.gov.uk/budget.

A meeting of the Monopolies and Mergers Commission. The meeting would hear representations from experts, the companies involved and other stakeholders. The students would be given a scenario in advance with the relevant data. Additional information could be given to each group. The student(s) playing the MMC would chair the discussion.

Each of the above could take place synchronously (that is, with all students

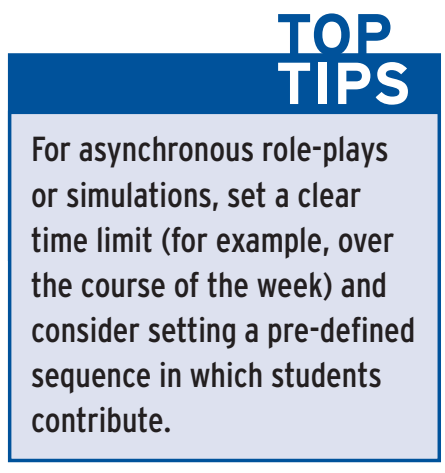
online simultaneously) in a scheduled time slot (such as a seminar hour). Alternatively, they could take place asynchronously, with students contributing at their convenience.

\subsection{Virtual seminars}

Virtual seminars can be used to extend overall contact with students and complement face-toface seminars, encouraging a more equitable contribution from students. They are particularly suitable for allowing students to develop their presentation and critiquing skills and to refine their ideas about concepts. This can be encouraged by pre-setting questions, to which students have to develop an answer that they then post on a discussion board during their virtual seminar. During face-to-face seminars these answers can be further critiqued, allowing students to engage in a deeper discussion of concepts.

\section{Case study 3: Virtual seminars using Blackboard John Sloman, University of the West of England, 2002}

http://www.economics.ltsn.ac.uk/showcase/sloman_workshop.htm

Virtual seminars are run fortnightly on a 1-year, 30-credit Economic Principles and Applications module. There are approximately 220 students on the module, divided into 12 seminar groups of approximately 18 students each. The students have two lectures per week, a whole-year workshop per week (with 220 students in the workshop), an in-class seminar fortnightly and a virtual seminar fortnightly at the same time as the in-class seminar on the alternate week. In any 
one week, six of the groups are having traditional in-class seminars and the other six are having virtual seminars.

The virtual seminars run in Blackboard, using the group discussion board facility. The seminars are synchronous: that is, students debate with each other for a set period, namely the seminar hour. But, the seminars being virtual, students can take part in them from anywhere: a computer lab, home, an internet café or wherever. For each seminar, a set of instructions are posted in advance. These include links to Web-based reading and some questions that the students must answer. The seminars are tightly structured. Having completed the reading, which students are encouraged to do in advance, they must first answer each of the questions (normally three) and then start responding to the answers that other students in the group have posted. The outline of the seminars and questions for students is presented in Figure 3.

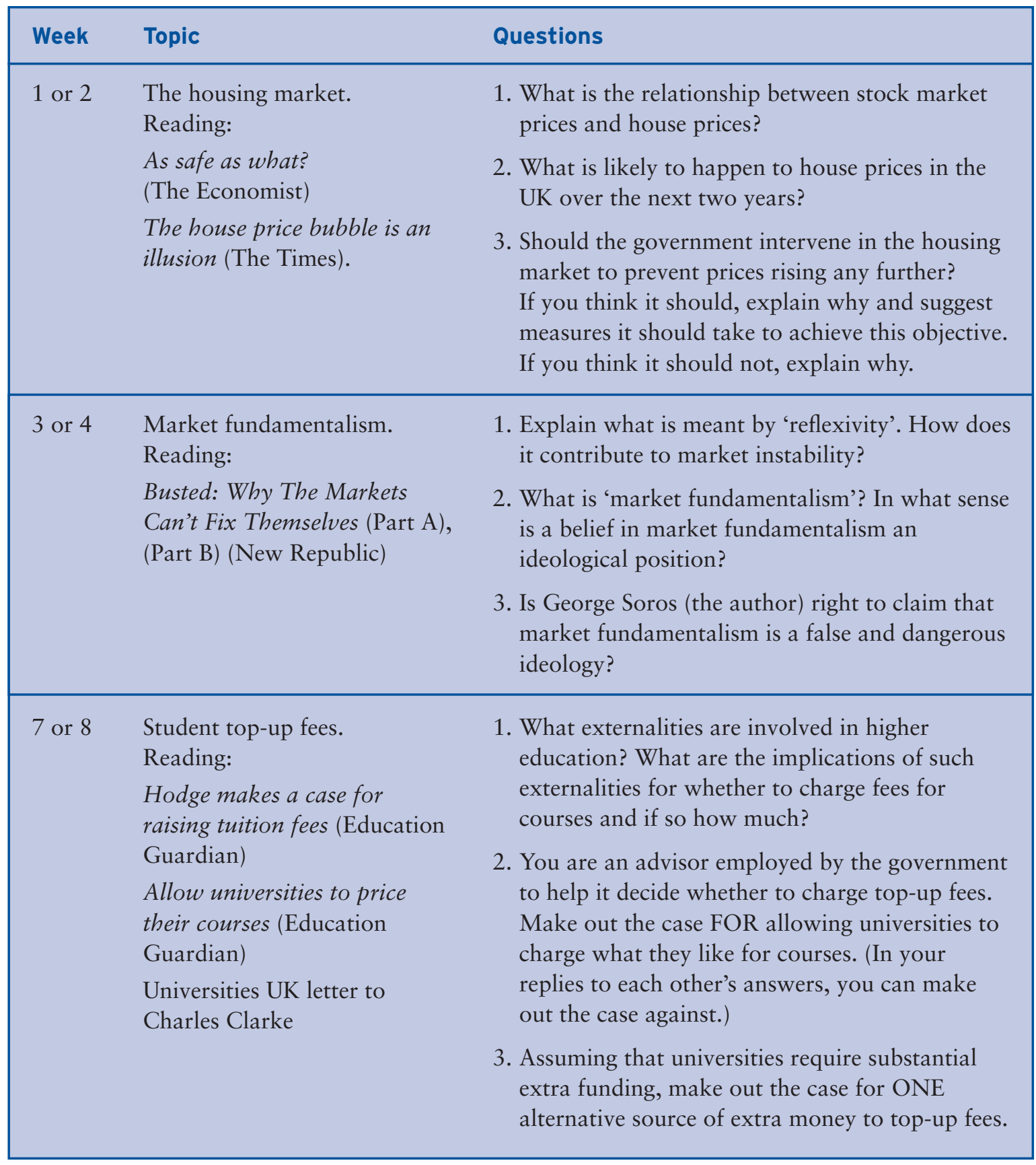

Figure 3. Examples from a seminar series using Blackboard. (Continued over). 


\begin{tabular}{|c|c|c|}
\hline Week & Topic & Questions \\
\hline 11 or 12 & $\begin{array}{l}\text { Essay marking exercise in preparation } \\
\text { for January test. Reading: } 4 \text { answers } \\
\text { to mini-essay question from last } \\
\text { year's test. These were 'anonymised' } \\
\text { and typed up and then hyperlinked } \\
\text { from the discussion board. }\end{array}$ & $\begin{array}{l}1,2,3 \text { and } 4 \text {. Post your mark and } \\
\text { comments here for the first/second/third/last } \\
\text { of the four essays. Later, when you have } \\
\text { done this for all four essays, you should } \\
\text { return to each essay, comment on what } \\
\text { other students in the group have had to say } \\
\text { and attempt to reach a consensus mark. }\end{array}$ \\
\hline 15 or 16 & $\begin{array}{l}\text { Setting part of the exam paper - five } \\
\text { essay questions on first term's work. } \\
\text { Each of the } 12 \text { groups' questions are } \\
\text { then posted on the whole-year } \\
\text { discussion board and students are } \\
\text { told that the first half of the actual } \\
\text { exam (five questions) will be drawn } \\
\text { from these } 60 \text { questions. }\end{array}$ & $\begin{array}{l}\text { In each of five sub-groups, students have to } \\
\text { set a question on a specific topic in the first } \\
\text { half of the module. The discussion board is } \\
\text { then used to refine the five questions and } \\
\text { arrive at an agreed group exam paper (first } \\
\text { half). }\end{array}$ \\
\hline 17 or 18 & $\begin{array}{l}\text { Role-playing exercise. Students are } \\
\text { assigned to five subgroups, } \\
\text { representing the WTO, the US } \\
\text { Administration, the EU Commission, } \\
\text { a group of developing countries and a } \\
\text { major environmental charity (e.g. } \\
\text { Greenpeace or Friends of the Earth). } \\
\text { They are then given the scenario that } \\
\text { the USA has introduced a new and } \\
\text { extensive range of trade restrictions to } \\
\text { protect US firms from 'cheap imports'. }\end{array}$ & $\begin{array}{l}\text { In role, each subgroup has to prepare a } \\
\text { response to the USA's actions (or, in the } \\
\text { case of the USA, a justification). Then, } \\
\text { chaired by the WTO group, discussion is } \\
\text { opened up for the groups to debate with } \\
\text { each other. }\end{array}$ \\
\hline
\end{tabular}

Figure 3. Examples from a seminar series using Blackboard.

The first two virtual seminars were conducted in a computer lab with a tutor present. This allowed the necessary support to be provided and the protocols to be established. Thereafter, students could take part in the seminars from any location of their choice. After the first two seminars, tutors are not present during the hour, and thus there is considerable saving in staff time. A tutor is assigned to each group, however, and within 3 days reads the discussion and posts a commentary on it. Students are then required to read the tutors' comments before they take part in the next virtual seminar. Students, if they wish, can add further comments to a debate after the completion of the hour, and each virtual seminar stays 'live' for the remainder of the academic year. Thus students can revisit each discussion for revision purposes and make further postings if they so choose.

Given that students in different groups often make similar points, tutors' comments can normally be simply amended from one group to another, rather than written from scratch. Tutor time is approximately 20 minutes per group: that is, a total of 2 hours per week for the six groups in that week - a saving of 4 staff hours per week for seminars. This gives a net saving of staff time of 2 hours per week (the workshops account for an extra 2 hours, since they are taken by two members of staff). Despite the saving in staff time, students have more class time. They have 4 hours per week of classes of one type or another, compared with the normal allocation of 3 hours. 
Virtual seminars are best suited to what might be called 'metaeconomics'. These involve students questioning assumptions behind policy objectives, relating economic concepts to current economic issues and discussing issues to do with the operation of the course, including learning and assessment. Given the limitations of the discussion board and virtual classroom in Blackboard and, in particular, the limitations of the whiteboard facility, students' contributions to the virtual seminars require the use of text only.

Students feel very comfortable operating in this environment, as most are familiar with chat

TOP TIPS

Ensuring that students are familiar with the technology and the protocols of virtual seminars is critical to the success of virtual seminars, as shown in the case study. rooms. It is important to stress to them, however, that this is an academic seminar and thus the debate should use 'proper' language and not 'chat speak'. It should also be made clear to students that they should avoid personal comments.

These virtual seminars have the advantage over real seminars that students can post simultaneously and thus make more contributions than in a traditional seminar. My experience is that students typically make between 6 and 8 postings each in the hour. Postings are typically between 3 and 4 lines, but are often up to 12 lines long, especially for the initial postings as opposed to the responses to other students' postings.

Virtual seminars also have the advantage that students' contributions are likely to be better thought-out than contributions in a traditional in-class seminar, where responses are often 'off the cuff'. They also give students a much more equal opportunity to contribute, and students who might be shy or hesitant in an in-class seminar seem quite happy contributing in the online environment. Conversely, the 'talkative' students, who can easily dominate an in-class seminar, seem to contribute no more than anyone else in a virtual seminar. Finally, the contributions remain visible for as long as that discussion board is accessible. Useful contributions in a traditional in-class seminar can quickly be forgotten; even if students make notes of other students' or tutors' contributions, they are often very sketchy.

In 2004 John Sloman is still using virtual seminars in his module, and he has now linked a small number of credit points of the module to the 'personal development profiles' that the students are required to fill in, where they have to reflect on the quality of their participation.

\subsection{Structured debates}

Structured debates using discussion boards can be a useful way to develop students' analytical and academic discussion skills. Each student can be assigned a role in the debate. For example:

- Proposer of the motion. The proposer's role is to post a short message to the discussion board, making a case for the proposition in such a way as to encourage comment from other group members.

- Opposer. The opposer's role is to counter the proposer's message by posting a message arguing for the opposite point of view, again in such a way as to encourage further comment.

- Moderator. The moderator's role is to set the overall scene for the discussion, to encourage initial comments on the proposer's and opposer's messages, to encourage 'lurkers' to contribute, to keep the discussion on track, and to weave (that is, make links between different contributors' messages).

- Documentalist. The documentalist's role is to summarise one or more of the set readings for the topic, picking out the points relevant to the proposition, and contribute the summary to the discussion thread.

- Researcher. The researcher's role is to go out and find other relevant readings and resources, from the Web and from the set books, and bring them to the attention of the group. 
- Rapporteur. The rapporteur's role is to prepare a summary of the overall debate and post it to the discussion board for comments by the group, at the end of the debate.

- Commenters. The commenters' role is to comment on the ideas put forward by all of the above and help keep the discussion going. This is a role that everyone in the could take on, in addition to the specific roles above.

The above roles have been taken from a real activity on the Open University's Applications of Information Technology in Open and Distance Education course (2004), where the students debated a question that later formed an assessed essay. The essay's criteria included reference to the debate and the extent to which the individual student contributed and developed ideas.

Economics debate questions could include:

- tax cuts;

- tighter environmental legislation;

- deregulation;

- the Private Finance Initiative;

- moving to a Taylor rule;

- increasing overseas aid;

- various reforms of the common agricultural policy.

\subsection{Master classes}

A master class involves giving access to a subject expert via a discussion board. This can be a good way for students to develop ideas and obtain expert feedback, but both students and expert need support to do this successfully.

\section{Case study 4: The use of visiting industrialists in a Health, Leisure, Sport and Tourism module Professor Andrew Lockwood, University of Surrey, 2004}

http://www.sole.ilrt.org/HLSTReport.pdf

This case study is drawn from the SOLE (Students' Online Learning Experiences) project case studies (www.sole.ilrt.org).

The module involved 400 students and focused on business research methods. Using Lotus Learning Space's discussion board, it involved a series of industry forums discussing industry problems introduced by 'visiting' industrialists. It was partly assessed by group-based case studies, involving data collection and

One way to run a master class
is to get the 'guest expert' to
start the discussion with a
prepared paper: it is a good-
idea to support this with a
'lead-in' from the tutor and
encouragement to a few
students to seed discussion
with questions or comments.
Following a larger discussion,
the activity can be rounded
off by a summary from the
expert.
analysis.

The industry forums were not immediately accepted as beneficial by the students, but largely at the end of the activity they were seen as useful. For example, one student decided that the forums were of no value and, using the discussion area, established a survey for all the other students to support her view. The tutors decided not to intervene, but became involved in the debate about the survey design itself and the industry problems that then arose. After further discussion, the survey found that the industry forums were strongly supported by students, and the student who developed the survey became one of the strongest advocates.

Students were asked what had contributed most to their learning and the overwhelming response was the interaction through the course discussion rooms and the group aspects of the work. A student commented about the group work: 
'the group work was different ... people had to link up to do it ... there was a lot of work outside it [the VLE] ... the group work had to be more organised than others'

From the tutors' perspective, using the discussion board in this way was invaluable when dealing with such a large cohort of students:

'I simply couldn't teach a large group without it ... it has made the approach possible ... I couldn't connect all these people in any other way ... to develop their own case study material but to keep control over what they are doing gives them the confidence and allows me to draw back as they develop more knowledge ... but it all needs to be planned in advance.'

This case study reflects the importance of allowing students to reflect on different and new methods of learning: in this case, working in groups and engaging in virtual discussion with industrial experts. The tutors' roles were very much about supporting and facilitating but not leading, allowing students to discuss and develop their own ideas.

\subsection{Co-operative/collaborative project work}

Using discussion boards for group co-operative/collaborative work can provide a flexible area for students to brainstorm and generate ideas, explore solutions, allocate and share tasks, produce a group report, evaluate each other's work and develop group skills. This can be particularly beneficial to wholly online courses where this is the main or only means of communication. Discussion boards can also be used to complement face-to face sessions. An electronic record of group work, which could include minutes of face-to-face meetings, is helpful for both students and tutors.

\section{Case study 5: Supporting face-to-face seminars with online group activity Géraldine Enjelvin, University College Northampton}

http://www.business.ltsn.ac.uk/resources/reflect/conf/2003/enjelvin/enjelvin.pdf

In a strategic business analysis level 2 module, discussion boards were used to support a face-toface course and to encourage more active and independent learning. Other objectives in using the discussion board included facilitating collaborative learning through group online activities and making seminars more learner-centred (students would have already discussed many of the course resources via the discussion board, so would more easily be able to provide information themselves rather than passively receiving information as in traditional lectures). The overall number of lectures on the course was reduced and an element of self-assessment focusing on students' participation within their discussion groups was introduced.

Most of the students felt that class contact time in seminars was used more effectively due to the use of the VLE and the discussion boards, but the majority also reported the opinion that an increase in face-to-face seminars would be more productive. Many students experienced technical problems and some students did not contribute to online discussion (the discussion board was using Learnwise and was still in a pilot stage at the university). The appropriateness of some of the materials used for discussion was also criticised.

Géraldine Enjelvin argues that the new approach did generally encourage deeper learning by students. She also concludes that tutors should be critical in their choice of materials and resources to support discussion, and should move from tightly guided or 'scaffolded' activity to more open, less guided activity (see section 2.7 ). She also recommended tutors to provide examples of critical and reflective thinking to help students engage with this type of learning.

Salmon (2002) offers many ideas and practical advice on online discussion activities in her book Etivities. 


\section{Conclusions}

This chapter has argued that online communication using discussion boards has an important role to play in teaching and learning economics, and has suggested practical tips and a variety of ways of using this technology effectively. Using discussion boards can enhance learning, offer students unique opportunities and potentially extend contact time with teachers. Effective use requires recognition of potential problems, including issues of text-only communication, linking to assessment and managing discussion, all of which can be resolved through careful design, preparation and organisation. Successful understanding of economics involves the ability to think and discuss critically, problem-solve and make decisions, and using discussion boards in a teaching strategy can provide students with opportunities to develop these skills in an engaging way.

\section{Where next?}

The following texts may be useful as further reading on the application of discussion boards to economics teaching.

Benfield, G. (2002) 'Designing and managing online discussion', Oxford Centre for Staff and Learning Development (OCSLD) Learning and Teaching Briefing Papers Series, online at http://www.brookes.ac.uk/services/ocsd/2_learntch/briefing_papers.html (last accessed 29 September 2004).

Garrison, D. R. and Anderson, T. (2003) E-Learning in the 21st Century: A Framework for Research and Practice, RoutledgeFalmer, London.

Higgison, C. (ed.) (2001) 'Online tutoring skills e-book and case studies', OTiS, online at http://otis.scotcit.ac.uk/onlinebook/ (last accessed 17 September 2004).

Littlejohn, A. and Higgison, C., 'A guide for teachers', LTSN Generic Centre e-Learning Series, no. 3, online at http://www.ltsn.ac.uk/application.asp?app=resources.asp\&process=full_record \&section=generic\&id=323 (last accessed 17 September 2004).

McAteer, E. and Harris, R., 'Computer-mediated conferencing', LTSN Generic Centre Starter Guide, no. 3, online at http://www.ltsn.ac.uk/application.asp?app=resources.asp\&process= full_record\&section=generic\&id=37 (last accessed 10 September 2004).

Salmon, G. (2000) E-moderating: The Key to Teaching and Learning Online, Kogan Page, London. 


\section{References}

Brown, R. (2001) 'The process of community-building in distance learning classes', Journal of Asynchronous Learning Networks, vol. 5, no. 2, pp. 18-35 (The Sloan Consortium), online at http://www.aln.org/publications/jaln/v5n2/v5n2_brown.asp (last accessed 10 September 2004).

Enjelvin, G. (2003) ““e-novation” on a Strategic Business Analysis module: reflection on action and reflection for action', conference proceedings, BEST Creativity and Innovation in Academic Practice, online at: http://www.business.ltsn.ac.uk/resources/reflect/conf/2003/ (last accessed 10 September 2004).

Freeman, M. A. and Capper, J. M. (1999) 'Exploiting the Web for education: an anonymous asynchronous role simulation', Australian Journal of Educational Technology, vol. 15, no. 1, pp. 95-116, online at http://www.ascilite.org.au/ajet/ajet15/freeman.html (last accessed 2 October 2004).

Freiermuth, M. (2001) 'Native speakers or non-native speakers: who has the floor? Online and face-to-face interaction in culturally mixed small groups', Computer Assisted Language Learning, vol. 14, no. 2, pp. 169-99.

Gilbert Hunt, S. and McLaine, T. (2000) 'Critical thinking and learning in health science', C. Higgison (ed.), Practitioners' Experiences in Online Tutoring: Case Studies from the OTiS eWorkshop, Heriot-Watt University and The Robert Gordon University, online at http://otis.scotcit.ac.uk/casestudy/gilbert-hunt.doc (last accessed 2 October 2004).

Goodyear, P. (2001) 'Effective networked learning in higher education: notes and guidelines', Lancaster University, online at http://csalt.lancs.ac.uk/jisc/advice.htm (last accessed 2 October 2004).

Hardy, V., Hodgson, V. and McConnell, D. (1994) 'Computer conferencing: a new medium for investigating issues in gender and learning', Higher Education, vol. 28, pp. 403-18.

Harvey, J (ed.) (1998) 'LTDI Evaluation Cook Book', LTDI, Edinburgh, online at http://www.icbl.hw.ac.uk/ltdi/ltdi-pub.htm\#Cookbook (last accessed 29 September 2004).

Kennedy, D. and Duffy, T. (2000) 'Understanding the effort', in C. Higgison (ed.) (2001) Practitioners. Experiences in Online Tutoring: Case Studies, OTiS, online at http://otis. scotcit.ac.uk/casestudy/kennedy.doc (last accessed 23 September 2004).

Klemm, W. R. and Snell, J. R. (1996) 'Enriching computer-mediated group learning by coupling constructivism with collaborative learning', Journal of Instructional Science and Technology, vol. 1, no. 2, pp. 1-11.

Lockheed, M. E. and Harris, A. M. (1984) 'Cross-sex collaborative learning in elementary classrooms', American Educational Research Journal, vol. 2, pp. 275-94.

McConnell, D., Lally, V. and Banks, S. (2004) 'Theory and design of networked learning communities', Proceedings of Networked Learning Conference 2004, Sheffield University, online at http://www.shef.ac.uk/nlc2004/Proceedings/Symposia/Symposium11/McConnell _et_al.htm (last accessed 10 September 2004).

Morse, K. (2004) 'International management: early experience in multicultural virtual team interaction', in R. Ottewill, L. Borredon, L. Falque, B. Macfarlane and A. Wall (eds), Educational Innovation in Economics and Business VIII: Pedagogy, Technology and Innovation, Kluwer Academic Publishers, Dordrecht, Netherlands. 
Oliver, M. and Conole, G. (1998) 'Evaluating communication and information technologies: a toolkit for practitioners', Active Learning, vol. 8, pp. 3-8 (Institute for Learning and Teaching), online at http://www.ilt.ac.uk/public/cti/ActiveLearning/al8pdf/oliver.pdf (last accessed 1 October 2004).

Open University (2004) 'Applications of Information Technology in Open and Distance Education course outline', Institute of Educational Technology, online at http://iet.open.ac.uk/coursesonline/ode/description.cfm\#H802 (last accessed 1 October 2004).

Ponti, M. and Ryberg, T. (2004) 'Rethinking virtual space as a place for sociability: theory and design implications', Proceedings of Networked Learning Conference 2004, Sheffield University, online

http://www.shef.ac.uk/nlc2004/Proceedings/Symposia/Symposium13/Ponti_Ryberg.htm (last accessed 10 September 2004).

Quality Assurance Agency for Higher Education (2000) 'Economics Subject Benchmark statement', online at http://www.qaa.ac.uk/crntwork/benchmark/economics.html (last accessed 1 October 2004).

Reynolds, P. (2000) 'Introduction', in P. Davies, S. Hodkinson and P. Reynolds (eds), Innovative Approaches to Learning and Teaching in Economics and Business Higher Education, Staffordshire University Press, Stoke on Trent.

Rovai, A. P. (2002) 'Building sense of community at a distance', International Review of Research in Open and Distance Learning, vol. 3, no. 1, pp. 1-16, Athabasca University, Canada, online at http://www.irrodl.org/content/v3.1/rovai.html (last accessed 10 September 2004).

Salmon, G. (2002) Etivities: The Key to Active Online Learning, Kogan Page, London.

Students' Online Learning Experiences (SOLE) (2003) 'Case studies' and (2004) 'Reports', Learning and Teaching Support Network (LTSN) and Joint Informations Systems Committee (JISC) project, online at http://www.sole.ilrt.org (last accessed 1 October 2004).

Tan, A. (1990) 'The language of discretion', in C. Ricks and L. Michaels (eds), The State of Language, Faber and Faber, London.

Ting-Toomey, S. (1999) Communicating across Cultures, Guilford Press: London.

Tinto, V. (1993) Leaving College: Rethinking the Causes and Cures of Student Attrition, 2nd edn, University of Chicago Press, Chicago, IL.

Vygotsky, L. S. (1978) 'Interaction between learning and development', trans. by M. LopezMorillas, in M. Cole, V. John-Steiner, S. Scribner and E. Souberman (eds), Mind in Society: The Development of Higher Psychological Processes, Harvard University Press, MA.

Wegerif, R. (1998) 'The social dimension of asynchronous learning networks', Journal of Asynchronous Learning Networks, vol. 2, no. 1, pp. 34-49 (The Sloan Consortium), online at http://www.aln.org/publications/jaln/v2n1/v2n1_wegerif.asp (last accessed 10 September 2004).

Zalpaska, A. M., Falnegin, F. and Rudd, D. (2004) 'Student feedback on distance learning with the use of WebCT', Computers in Higher Education Economics Review, vol. 16, no. 1, pp. 10-14, Economics LTSN, online at: http://www.economics.ltsn.ac.uk/cheer/ch16/ (last accessed 10 September 2004). 